\title{
In Reply: Fellowships and subspecialization in anesthesia: Are they good, bad, or both?
}

\author{
James S. Khan, MD $\cdot$ Jaclyn Gilbert, MD $\cdot$ Abhinav Sharma, MD $\cdot$ Doreen Yee, MD
}

Received: 1 March 2016/Accepted: 8 March 2016/Published online: 5 April 2016

(C) Canadian Anesthesiologists' Society 2016

\section{To the Editor,}

We thank Dr. Mutter for his insightful comments ${ }^{1}$ regarding our article on the perspectives of anesthesia residents training in Canada on fellowship pursuits. ${ }^{2}$ Fellowship training objectives have long been diverse and varied, and they frequently vary among hospitals, university departments, and fellows' goals. Although it is possible that some of the subspecialty areas may come under some form of regulation by one of our national bodies, we do not believe that this level of regulation is required for all clinical fellowships as it would contribute to unnecessary "credential creep." Each university department, in conjunction with hospital departments, should provide oversight to ensure that the fellows value their experience.

Certainly, a conflict of interest may exist if a faculty member or department advises a resident to pursue

\section{J. S. Khan, MD ( $ه) \cdot D$. Yee, MD}

Department of Anesthesia, University of Toronto, Toronto, ON, Canada

e-mail: james.khan@medportal.ca

J. Gilbert, MD

Department of Anesthesia, McMaster University, Hamilton, ON, Canada

A. Sharma, MD

Duke University, Durham, NC, USA

D. Yee, MD

Department of Anesthesia, Sunnybrook Health

Sciences Centre, Toronto, ON, Canada fellowship training, especially if the fellowship position is at the respective institution. This is an important issue given that approximately $27 \%$ of residents are influenced by advice from their mentors or program director. ${ }^{2}$ Conflicts of interest should be recognized and managed in a way that allows both parties to benefit in a stable system that is not only sustainable over time but evolves to accommodate the changing environment of job availability, economics, and models of care.

Although subspecialty training may result in a decline in confidence and, potentially, competence in broad-based anesthetic practice, there are no data of which we are aware that supports this notion. Furthermore, most anesthesia fellowships include clinical work beyond the subspecialty area, especially when it comes to on-call coverage. Fellowship training may also be a valuable transition to independent practice as it offers clinical independence with the advantage of access to help and advice from staff consultants.

We agree with Dr. Mutter's ideal that subspecialization should be done "in the right way and for the right reasons." However, pursing fellowship training because of real or perceived job market strains may not be completely disadvantageous. Because the majority of residents intend to pursue a fellowship, ${ }^{2}$ simply obtaining one is no longer "good enough" to get a job. Excellence not only at the resident level but at the fellowship level is now required. A high standard is not only beneficial to the individual and respective department but ultimately to the patients and communities who are served.

Conflicts of interest None declared.

Editorial responsibility This submission was handled by Dr. Hilary P. Grocott, Editor-in-Chief, Canadian Journal of Anesthesia. 


\section{References}

1. Mutter TC. Fellowships and subs»pecialization in anesthesia: Are they good, bad, or both? Can J Anesth 2016; 63. DOI:10.1007/ s12630-016-0627-9.
2. Khan J, Gilbert J, Sharma A, LeManach Y, Yee D. Perspectives of anesthesia residents training in Canada on fellowship training, research, and future practice location. Can J Anesth 2015; 62: 956-63. 